\title{
Analysis and design of class-E power amplifier considering MOSFET nonlinear capacitance
}

\author{
Dat Vuong, Tran The Son, Anh Phan Thi Lan, Hien Dang Quang, Trang Nguyen \\ Vietnam-Korea University of Information and Communication Technology, University of Danang, Da Nang City, Vietnam
}

\begin{abstract}
Article Info
Article history:

Received Apr 27, 2021

Revised Jan 20, 2022

Accepted Jan 27, 2022

\section{Keywords:}

Class-E amplifier

High power added efficiency

(PAE)

MOSFET

Nonlinear capacitance

Switch-mode

ABSTRACT

Class-E power amplifiers are integrated into many applications because their simple design and high performance. The efficiency of the power amplifier is significantly impacted by the nonlinear characteristic of the switching device, which is not analyzed clearly in theory. The nonlinear drain-tosource parasitic capacitance of the power transistor and the linear external capacitance are both contributed to the optimum conditions for obtaining the exact shunt capacitance. In this paper, a high-efficiency class-E power amplifier with shunt capacitance is designed with the consideration of both linear and nonlinear capacitance. Furthermore, a mathematical analysis is derived to calculate the component values in order to design the class-E power amplifier. Consequently, high power-added efficiency of $94.6 \%$ is obtained using MRF9030 MOSFET transistor with parameter of 4W output power and $13.56 \mathrm{MHz}$ operating frequency. Finally, the measurement result of a linear class-E power amplifier circuit is obtained to compare and realize the efficiency of the proposed work.
\end{abstract}

This is an open access article under the $\underline{C C B Y-S A}$ license.

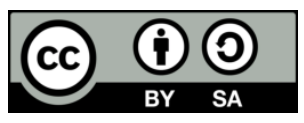

\section{Corresponding Author:}

Dat Vuong

Vietnam-Korea University of Information and Communication Technology, University of Danang The headquarters is at Danang University Urban Area, Nam Ky Khoi Nghia Street, Ngu Hanh Son District, Da Nang City, Vietnam

Email: vcdat@vku.udn.vn

\section{INTRODUCTION}

The main purpose of power amplifier system is reducing significantly the power consumption to optimize the efficiency of system operation. One of the most important factors that impact on such efficiency, is power added efficiency (PAE) [1]-[7]. There are several switch-mode amplifier structures such as class-E, D, F, and inverse class-F power amplifier have been introduced to archive high efficiencies. Each switchmode class has some advantages and disadvantages depending on the specific application [8]-[12]. For instance, the class-D power amplifier is suitable for audio and RF frequencies application. Therefore, this amplifier archives low efficiency at high frequencies because a remarkable energy loss is caused of parasitic reactance of the device [13]. Meanwhile, the class-F and the inverse class-F power amplifier are proposed to control harmonic components in case of operating in a saturation region of the device in order to mitigate overlapping between waveform of current and voltage. Unfortunately, a certain large number of harmonics has to put under control to improve the efficiency [14], [15]. Therefore, the harmonic controlling circuit becomes extremely complex and voluminous.

The integration of class-E power amplifier and a shunt capacitor was manufactured with the PAE theoretically reaching nearly $100 \%$ [16]-[18]. However, the actual operation of a linear shunt capacitance factor in class E power amplifier is not similar to its theoretical analysis. The overall value of shunt capacitance is significantly increased by nonlinear of switch component, specifically, its parasitic drain-to- 
source capacitance. Therefore, regarding to the operation of the class-E power amplifier, the nonlinear capacitance must be considered. In [19], [20], the author presented an analysis and design method of the class $\mathrm{E}$ amplifier for both nonlinear and linear shunt capacitance. In this work, in order to figure out results of a numerical analysis of the design equations for extracting the component values in the class E amplifier, the supported figures and tables is examed. However, the analysis neglected the dependence of the junction capacitance on the characteristic capacitance of the transistor leading to an inaccurate capacitance extraction. Therefore, to design a class-E power amplifier integrated both a nonlinear and linear capacitance, the equations should be solved for a specific MOSFET transistor without the inheritance of the design process in previous literature.

In this paper, the class-E power amplifier with nonlinear and linear capacitance are a deeply analyzed to explain the dependence of the shunt capacitance with the specific MOSFET transistor to calculate the accurate nonlinear capacitance. A mathematical analysis is derived to archieve electronic component values of the circuit. In addition, the equations of a specific MOSFET transistor depend on its own parameters. A design process of the class-E power amplifier is presented to obtain the maximized PAE for an arbitrary MOSFET transistor. The zero-voltage switching (ZVS) and zero-voltage-derivative switching (ZVDS) conditions are used to obtain the exact components for the power amplifier, which ensure minimizing switching loss, low noise, and enhances component tolerances [21]-[25]. In addition, the PAE of the proposed work is compared with the linear capacitance class-E amplifier to evaluate efficiency improvement. Finally, the proposed power amplifier is fabricated and measured to verify the high performance with the exactly calculated nonlinear capacitance.

This paper is organized as follows. The circuit analysis and extracted parameters for the components of the class-E power amplifier are presented in section 2 . The mathematical equations are founded to evaluate the dependence of the nonlinear capacitance on the operating frequency. The fabrication and measurement of the proposed class-E power amplifier are demonstrated in section 3. Finally, a comparison between the proposed method and a linear class-E power amplifier is shown to present the efficiency improvement.

\section{CIRCUIT ANALYSIS AND PARAMETERS}

The integrated circuit between class-E amplifier and shunt capacitance is illustrated in Figure 1. The MOSFET transistor plays as a switch device and the series resonant circuit is RLC. $C_{0}$ and $C_{e}$ are MOSFET drain-to-source capacitance and the external linear capacitance of the shunt capacitance respectively. The equation of total shunt $C_{\text {shunt }}$ is given:

$$
C_{\text {shunt }}=C_{0}+C_{e}=\frac{C_{j 0}}{\sqrt{1+\frac{v_{s}}{V_{b i}}}}+C_{e}
$$

where $v_{s}$ and $V_{b i}$ are the drain-to-source voltage and the built-in potential of the MOSFET body diode respectively, and $C_{j 0}$ is defined as the shunt capacitance at $v_{S}=0 \mathrm{~V}$.

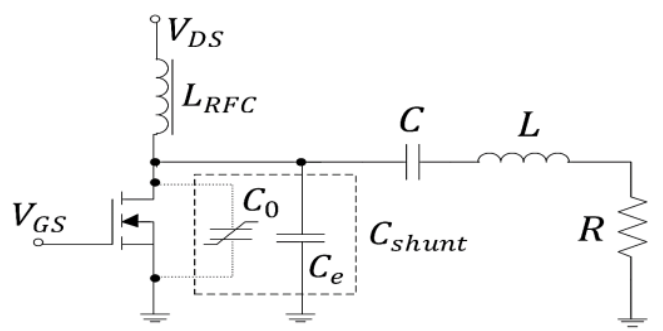

Figure 1. The circuit of class-E power amplifier

During the operating time, the switch voltage has to adapt the ZVS condition. Because the measured value of the dc component of the voltage drop across the choke inductor LRC is zero, the dc supply voltage $\mathrm{V}_{D S}$ is equal the average value of the switch voltage and depends on the drain-to-source voltage $v_{S}$ in case the status of switch is off, i.e for $0<\theta=\omega t \leq 2 \pi$ :

$$
V_{D S}=\frac{1}{2 \pi} \int_{0}^{2 \pi} v_{S}(\theta) d \theta
$$

The drain-to-source voltage $v_{s}$ can be extracted by the integration of the drain current in (3): 


$$
\omega \int_{0}^{v_{s}}\left(\frac{C_{j 0}}{\sqrt{1+\frac{v_{s}}{V_{b i}}}}+C_{e}\right) d v_{s}=\int_{0}^{\theta} i_{C} d \theta
$$

Substituting the $v_{s}$ into in (2) and then expanding, we obtain the equation as followed:

$$
\begin{aligned}
& \frac{V_{D S}}{V_{b i}}=\frac{\delta}{\pi}\left[\pi(\delta+\beta \sin \emptyset \cos \emptyset+1)+\beta\left(\frac{\pi^{2}}{2}+2\right) \sin ^{2} \emptyset\right]-\frac{\delta}{\pi} \int_{0}^{\pi}\left[\delta^{2}+2 \delta+1+\right. \\
& \left.2 \delta \beta \sin \emptyset \cos \emptyset 2 \delta \beta \theta \sin ^{2} \emptyset-2 \delta \beta \sin \emptyset \cos (\beta+\emptyset)\right]^{\frac{1}{2}} d \theta
\end{aligned}
$$

Where:

$$
\beta=\frac{V_{D S}}{2 \pi f R C_{j 0} V_{b i}} \text { and } \delta=\frac{C_{j 0}}{C_{e}}
$$

and $\emptyset$ is the phase difference between input and output signals.

A nonlinear function of optimization was applied to the in (4) with the aim of obtaining an analysis solution through using the toolbox of MATLAB software because this equation could not be integrated. The solution is shown in Figure 2 that describe the dependence of $\delta$ and the operating frequency $f$ with the given values of $V_{D S}$ and $P_{0}$. From this figure, it is obvious to determine the ratio $\delta$ of the junction capacitance $C_{j 0}$ and the external capacitance $C_{e}$ at a specification frequency. Therefore, the external capacitance $C_{e}$ can be obtained by deducing from the $C_{j 0}$ :

$$
C_{j 0}=\left(C_{o s s}-C_{r s s}\right) \sqrt{1+\frac{25}{V_{b i}}}
$$

where $C_{o s s}$ and $C_{r s s}$ which are given in datasheet of MOSFETs, are in turn the output capacitance and reverse transfer capacitance of the transistor. Moreover, in (4), the junction capacitance $C_{j 0}$ is still exising in $\beta$, which infers from the parasitic parameters of the transistor. Consequently, the result of the in (4) is obtained for only the transistor that has the extracted $C_{j 0}$.

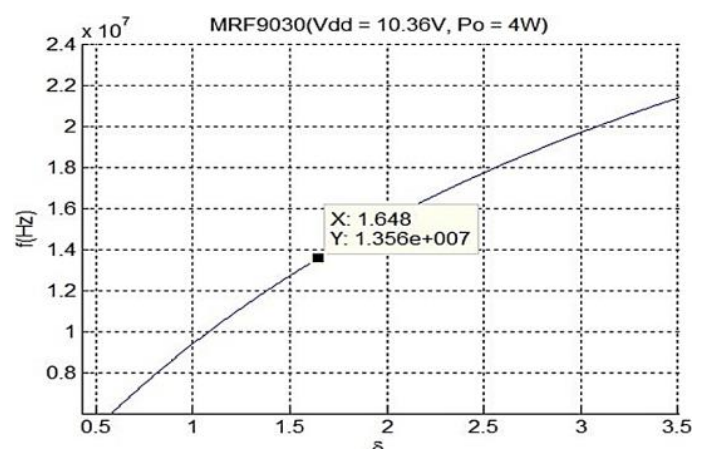

Figure 2. The relationship between frequency $f$ and dependence of $\delta$

The remained component values of circuit in Figure 1 can be calculated by:

$$
\begin{aligned}
& R=\frac{8 V_{D S}^{2}}{\left(\pi^{2}+4\right) P_{0}} \\
& X=R \tan (\varnothing+0.567) \\
& L=\frac{R Q}{\omega} \text { and } C=\frac{1}{\omega(R Q-X)}
\end{aligned}
$$

Where $Q$ is the quality factor. Then, the choke inductor $L_{R F C}$ is calculated as:

$$
L_{R F C}=2\left(\frac{\pi^{2}}{4}+1\right) \frac{R}{f}
$$

Since the above analyzed results, the designed schematic design of class-E power amplifier circuit is depicted in Figure 3. Regarding to this schematic, to minimize the power loss, the output load matching 
network is constructed by $L_{o-\text { match }}$ and $C_{o-\text { match }}$ to shape the output voltage and current. Meanwhile, $L_{i-\text { match }}$ and $C_{i-\text { match }}$ are two factors which constitute the input combining network. However, these factors do not have many effects on the total circuit performance. Figure 4 depicts the simulated voltage and current waveform under the optimum operation. There is a slight overlap with each other that leads to the minimized power attenuation on the MOSFET. The voltage across the switching device is proved to satisfy the ZVS and ZVDS conditions. Therefore, the class-E amplifier with the nonlinear capacitance consideration presents an approximately perfect operation of an idea class-E power amplifier.

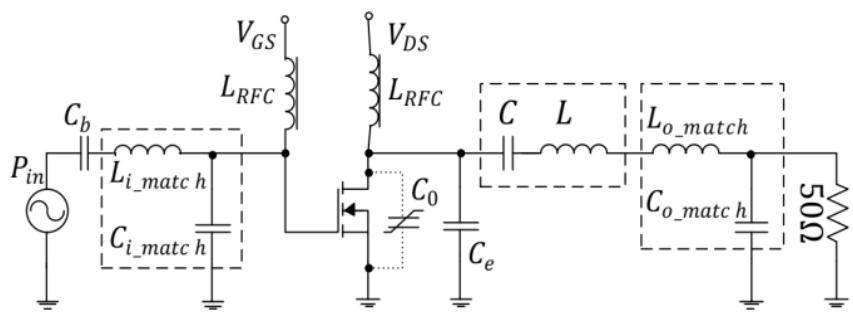

Figure 3. The designed circuit of class-E power amplifier

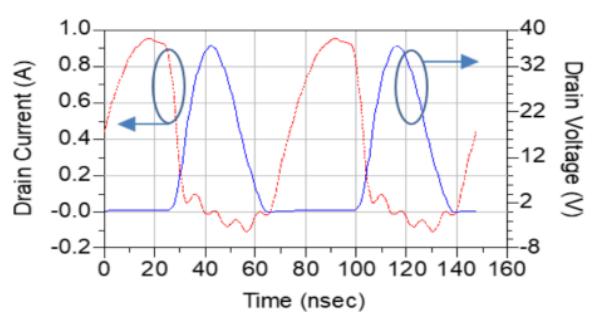

Figure 4. The simulation waveforms of drain current and voltage

\section{CIRCUIT DESIGN AND PERFORMANCE EVALUATION}

The proposed circuit of class-E power amplifier was fabricated to evaluate the performance using an MRF9030 MOSFET. From the above analysis, the component values were calculated, simulated, and implemented as demonstrated in Table 1. The values in the simulation and measurement are optimized for accumulating the highest efficiency cause a slight difference. Figure 5 shows the experimental results of the proposed circuit. The output power is measured using an Agilent 85665EC spectrum analyzer. Because the spectrum analyzer is limitated at maximum measurement output of $30 \mathrm{dBm}$, and an attenuator of $-37.67 \mathrm{~dB}$ is added at the end of the circuit. Finally, the output power is achieved at $36 \mathrm{dBm}$ or $3.98 \mathrm{~W}$, which is the sum of the attenuator and the measurement value in the monitor of the analyzer network. The PAE value of $94.6 \%$ is extracted by:

$$
P A E=\frac{P_{\text {out }}-P_{\text {in }}}{P_{d c}}=\frac{P_{\text {out }}-P_{\text {in }}}{V_{G S} I_{G S}+V_{D S} I_{D S}}=\frac{P_{\text {out }}-P_{\text {in }}}{V_{D S} I_{D S}} \%
$$

Table 1. The comparision of parameter class-E in different methods

\begin{tabular}{cccc} 
Components & Calculation & Simulation & Measurement \\
\hline$C_{e}$ & $111 \mathrm{pF}$ & $111 \mathrm{pF}$ & $110 \mathrm{pF}$ \\
$C$ & $86 \mathrm{pF}$ & $82 \mathrm{pF}$ & $82 \mathrm{pF}$ \\
$L$ & $1.8 \mathrm{uH}$ & $1.8 \mathrm{uH}$ & $1.8 \mathrm{uH}$ \\
$L_{R F C}$ & $7.9 \mathrm{uH}$ & $8.2 \mathrm{uH}$ & $10 \mathrm{uH}$ \\
$L_{o-\text { match }}$ & & $270 \mathrm{uH}$ & $270 \mathrm{uH}$ \\
$C_{o-\text { match }}$ & & $360 \mathrm{pF}$ & $360 \mathrm{pF}$ \\
$L_{i-\text { match }}$ & & $270 \mathrm{uH}$ & $270 \mathrm{uH}$ \\
$C_{i-\text { match }}$ & & $91 \mathrm{pF}$ & $91 \mathrm{pF}$ \\
\hline
\end{tabular}

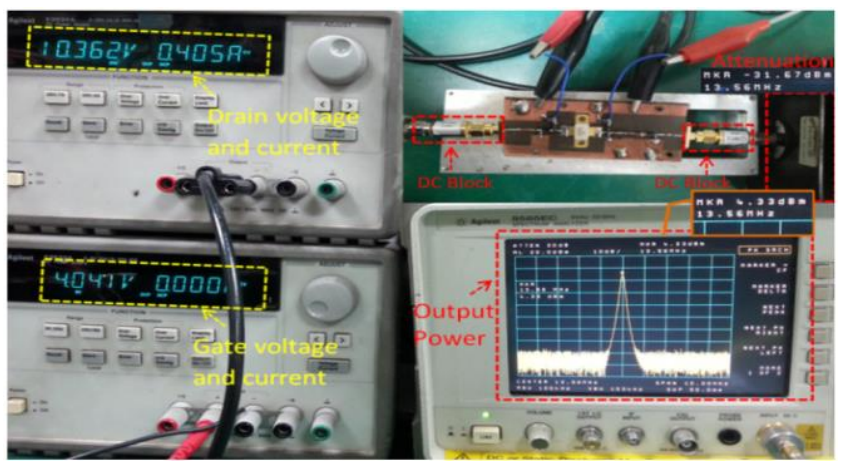

Figure 5. Measurement of class-E power amplifier circuit 
The gate-to-source current IGS can be ignored or appropriately zero. The drain-to-source voltage VDS and gate-to-source voltage $V_{G S}$ are supplied by $10.36 \mathrm{~V}$ and $4 \mathrm{~V}$, respectively. The external capacitor $C_{e}$ is chosen by the calculation based on the dependence of the $\delta$ value on the frequency for a specific condition. A comparison between the simulation and experiment results of the gain and PAE has a remarkable outcome, as shown in Figure 6. The highest PAE of the proposed amplifier can be obtained at $10 \mathrm{dBm}$ input power and power gain of $25 \mathrm{~dB}$. The system can maintain the PAE higher than $80 \%$ with the lowest input power of approximately $3 \mathrm{dBm}$, which presents a good performance of the proposed class-E power amplifier. To evaluate the efficiency of the proposed nonlinear capacitance class-E power amplifier, the design of the linear shunt capacitance class-E PAE circuit was experimented to compare the performance. The design method of the linear shunt capacitance class-E amplifier is referred to as the set of equations, which is presented by Sokal [11]. A contrast between two amplifiers with parameter values and efficiency is shown in Table 2. The total shunt capacitance in two cases has a tolerance of $60 \mathrm{pF}$. In the linear shunt capacitance class-E circuit, the drain current is higher than the one in the proposed circuit; whereas, the output power is lower. Therefore, the dissipated power in the switch device is increased significantly in the linear class-E amplifier, which has about $8 \%$ of PAE less than the proposed circuit. In consequence, to compare with the conventional linear of class-E power amplifier, the PAE of the class-E power amplifier with a consideration of nonlinear capacitance for a specific condition can be improved significantly.

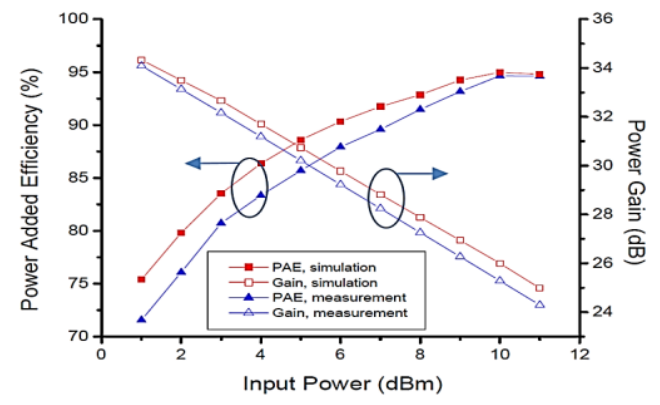

Figure 6. The result of gain and PAE in both simulation and measurement
Table 2. Comparison between the linear and composed of linear and nonlinear shunt capacitance class-E amplifier

\begin{tabular}{ccc}
\multicolumn{3}{c}{ circuits } \\
\hline Parameters & Linear circuit & Proposed circuit \\
\hline$V_{D S}$ & $10.36 \mathrm{~V}$ & $10.36 \mathrm{~V}$ \\
$V_{G S}$ & $4 \mathrm{~V}$ & $4 \mathrm{~V}$ \\
$I_{D S}$ & $0.412 \mathrm{~A}$ & $0.405 \mathrm{~A}$ \\
$I_{G S}$ & $0 \mathrm{~A}$ & $0 \mathrm{~A}$ \\
$C_{e}$ & $170 \mathrm{pF}$ & $110 \mathrm{pF}$ \\
$P_{\text {in }}$ & $10 \mathrm{dBm}$ & $10 \mathrm{dBm}$ \\
$P_{\text {out }}$ & $35.67 \mathrm{dBm} / 3.69 \mathrm{~W}$ & $36 \mathrm{dBm} / 3.98 \mathrm{~W}$ \\
$P A E$ & $86.2 \%$ & $94.6 \%$ \\
\hline
\end{tabular}

\section{CONCLUSION}

This work analyzed a practical class-E power amplifier circuit, which was designed using the composition of the nonlinear drain-to-source capacitance of the switching device and the external linear capacitance. A mathematical analysis is derived to obtain the exact value of the external capacitance. The PAE value of the proposed technique is improved significantly in comparison to the linear class-E circuit. The measured results indicated that a high result of PAE of $94.6 \%$ is achieved at $4 \mathrm{~W}$ output power level and 13.56 MHz operating frequency.

\section{ACKNOWLEDGEMENTS}

The authors would like to thank Dr. Nam Ha-Van from the Department of Electronics and Nanoengineering, Aalto University, Finland for his technical advice.

\section{REFERENCES}

[1] F. Raab, "Idealized operation of the class E tuned power amplifier," IEEE Transactions on Circuits and Systems, vol. 24, no. 12, pp. 725-735, 1977, doi: 10.1109/TCS.1977.1084296.

[2] M. Kazimierczuk and K. Puczko, "Exact analysis of class E tuned power amplifier at any Q and switch duty cycle," IEEE Transactions on Circuits and Systems, vol. 34, no. 2, pp. 149-159, 1987, doi: 10.1109/TCS.1987.1086114.

[3] N. H. Van and C. Seo, "Design of high PAE class-E power amplifier for wireless power transmission," IEICE Electronics Express, vol. 11, no. 7, pp. 1-6, 2014, doi: 10.1587/elex.11.20140682.

[4] N. H. Van, N. D. Duy, and C. Seo, "Frequency limitation of an optimum performance class-E power amplifier," IEICE Electronics Express, vol. 11, no. 7, pp. 1-6, 2016, doi: 10.1587/elex.13.20160108.

[5] N. D. Duy, N. H. Van, and C. Seo, "A Highly Efficient Broadband Class-E Power Amplifier with Nonlinear Shunt Capacitance," Journal of electromagnetic engineering and science, vol. 17, no. 4, pp. 221-227, 2017, doi: 10.26866/jees.2017.17.4.221.

[6] N. D. Duy, N. H. Van, and C. Seo, "Design of a highly efficient broadband class-E power amplifier with a low Q series resonance," Journal of electromagnetic engineering and science, vol. 16, no. 3, pp. 143-149, 2016, doi: 10.5515/JKIEES.2016.16.3.143. 
[7] E. Barmala , "Design and simulate a doherty power amplifier using GaAs technology for telecommunication applications," Indonesian Journal of Electrical Engineering and Computer Science, vol. 15, no. 2, pp. 845-854, 2019, doi: 10.11591/ijeecs.v15.i2.pp845-854.

[8] F. H. Raab, "Class-E, Class-C, and Class-F power amplifiers based upon a finite number of harmonics," IEEE Transactions on Microwave Theory and Techniques, vol. 49, no. 8, pp. 1462-1468, 2001, doi: 10.1109/22.939927.

[9] S. D. Kee, I. Aoki, A. Hajimiri and D. Rutledge, "The class-E/F family of ZVS switching amplifiers," IEEE Transactions on Microwave Theory and Techniques, vol. 51, no. 6, pp. 1677-1690, 2003, doi: 10.1109/TMTT.2003.812564.

[10] B. Kirish, F. Zubir, M. Kamal A. Rahim, and S. M. Shah, "Comparative Analysis of Sokal's Equations versus Load-Pull Implementation of Class E Low-Pass Network," Indonesian Journal of Electrical Engineering and Computer Science, vol. 19, no. 3, pp. 1348-1357, 2020, doi: 10.11591/ijeecs.v19.i3.pp 1348-1357.

[11] O. T. Weng, S. Isaak, Y. Yusof, "Low Power CMOS Electrocardiogram Amplifier Design for Wearable Cardiac Screening," International Journal of Electrical and Computer Engineering (IJECE), vol. 8, no. 3, pp. 1830-1836, 2018, doi: 10.11591/ijece.v8i3.pp1830-1836.

[12] M. Ribate, R. Mandry, J. Zbitou, L. E. Abdellaoui, A. Errkik, and M. Latrach, "1.25 GHz - 3.3 GHz broadband solid state power amplifier for L and S bands applications," International Journal of Electrical and Computer Engineering (IJECE), vol. 9, no. 5, pp. 3633-3641, 2019, doi: 10.11591/ijece.v9i5.pp3633-3641.

[13] S. A. El-Hamamsy, "Design of high-efficiency RF Class-D power amplifier," IEEE Transactions on Power Electronics, vol. 9, no. 3, pp. 297-308, 1994, doi: 10.1109/63.311263.

[14] A. Grebennikov and N. O. Sokal, "Switchmode RF Power Amplifiers," Elsevier, 2007.

[15] F. H. Raab, "Class-F power amplifiers with maximally flat waveforms," IEEE Transactions on Microwave Theory and Techniques, vol. 45, no. 11, pp. 2007-2012, 1997, doi: 10.1109/22.644215.

[16] N. O. Sokal and A. D. Sokal, "Class E-A new class of high-efficiency tuned single-ended switching power amplifiers," IEEE Journal of Solid-State Circuits, vol. 10, no. 3, pp. 168-176, 1975, doi: 10.1109/JSSC.1975.1050582.

[17] K. Chen and D. Peroulis, "Design of Highly Efficient Broadband Class-E Power Amplifier Using Synthesized Low-Pass Matching Networks," IEEE Transactions on Microwave Theory and Techniques, vol. 59, no. 12, pp. 3162-3173, 2011, doi: 10.1109/TMTT.2011.2169080.

[18] H. Xu, S. Gao, S. Heikman, S. I. Long, U. K. Mishra and R. A. York, "A high-efficiency class-E GaN HEMT power amplifier at 1.9 GHz,” IEEE Microwave and Wireless Components Letters, vol. 16, no. 1, pp. 22-24, 2006, doi: 10.1109/LMWC.2005.861355.

[19] T. Suetsugu and M. K. Kazimierczuk, "Analysis and design of class E amplifier with shunt capacitance composed of nonlinear and linear capacitances," IEEE Transactions on Circuits and Systems I: Regular Papers, vol. 51, no. 7, pp. 1261-1268, 2004, doi: 10.1109/TCSI.2004.830695.

[20] T. Suetsugu and M. K. Kazimierczuk, "Comparison of class-E amplifier with nonlinear and linear shunt capacitance," IEEE Transactions on Circuits and Systems I: Fundamental Theory and Applications, vol. 50, no. 8, pp. 1089-1097, 2003, doi: 10.1109/TCSI.2003.815208.

[21] X. Wei, H. Sekiya, S. Kuroiwa, T. Suetsugu and M. K. Kazimierczuk, "Design of Class-E Amplifier With MOSFET Linear Gateto-Drain and Nonlinear Drain-to-Source Capacitances," IEEE Transactions on Circuits and Systems I: Regular Papers, vol. 58, no. 10, pp. 2556-2565, 2011, doi: 10.1109/TCSI.2011.2123490.

[22] Z. Kaczmarczyk and W. Jurczak, "A Push-Pull Class-E Inverter With Improved Efficiency," IEEE Transactions on Industrial Electronics, vol. 55, no. 4, pp. 1871-1874, 2008, doi: 10.1109/TIE.2007.907665.

[23] M. Hayati, A. Lotfi, M. K. Kazimierczuk and H. Sekiya, "Analysis and Design of Class-E Power Amplifier With MOSFET Parasitic Linear and Nonlinear Capacitances at Any Duty Ratio,” IEEE Transactions on Power Electronics, vol. 28, no. 11, pp. 5222-5232, 2013, doi: 10.1109/TPEL.2013.2247633.

[24] A. Mediano, P. Molina-Gaudo and C. Bernal, "Design of Class E Amplifier With Nonlinear and Linear Shunt Capacitances for Any Duty Cycle," IEEE Transactions on Microwave Theory and Techniques, vol. 55, no. 3, pp. 484-492, March 2007, doi: 10.1109/TMTT.2006.890512.

[25] M. J. Chudobiak, "The use of parasitic nonlinear capacitors in class E amplifiers," IEEE Transactions on Circuits and Systems I: Fundamental Theory and Applications, vol. 41, no. 12, pp. 941-944, 1994, doi: 10.1109/81.340867.

\section{BIOGRAPHIES OF AUTHORS}

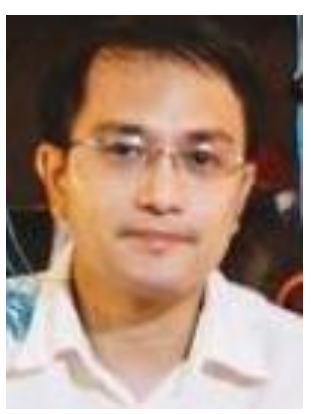

Dat Vuong (iD ) SI SC received the B.Eng degree in telecommunication and electronic engineering from the University of Sience and Technology, the University of Da Nang, Vietnam, in 2010, and the M.Sc. Degree in telecommunication and electronic engineering from Sheffield Hallam University, Sheffield, U.K, in 2013. He got the Ph.D. degree with the school of Electronic Egineering, Soongsil University, South Korea, in 2018. His research interests include wireless communication, visible light communication, antenna communication. He is currently lecturer of Viet - Korea University of Information and Communication Technology. He can be contact at email: vcdat@vku.udn.vn. 

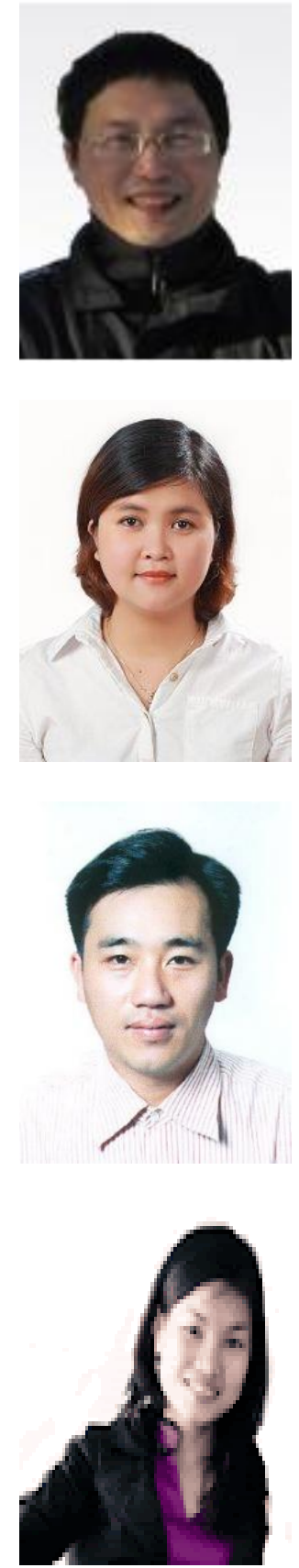

Tran The Son (iD SC SC P received the B.Eng and MSc at the University of Science and Technology of Da Nang, Vietnam in 1998 and 2004 respectively. In 2014, he has been awarded $\mathrm{PhD}$ degree at the Faculty of Engineering and Environment at Northumbria University, UK. He has served as TPC members or chairs of a variety of international conferences such as ACIIDS, ICCCI, and PRMIC. His research interests include routing in mobile ad-hoc networks, network security, QoS-aware routing, visible light communication, reverse engineering. He can be contact at email:_sontt@ viethanit.edu.vn.

Anh Phan Thi Lan (iD) 8 SC $\mathrm{P}$ received the B.Eng. degree in telecommunication and electronic engineering from the University of Science and Technology, The University of Da Nang, Vietnam, in 2010, and the M.Sc degree in electronic engineering from Da Nang University.in 2014. She got the Ph.D. degree with the School of Electronic Engineering, Soongsil University, South Korea, in 2020. Her research interests include wireless communication and visible light communication. She can be contact at email: ptlanh@vku.udn.vn.

Hien Dang Quang (D) IS SC P received the B.S. degree in information technology from the University of Science and Technology in 2004 and the M.S. degree in information technology from The University of Da Nang, Vietnam, in 2011. He got the PhD degree from the school of Electronic Engineering, Soongsil University, South Korea, in 2017. His research interests include visible light communication, computer wireless network and networksecurity. He can be contact at email: dqhien@vku.udn.vn.

Trang Nguyen (iD 8 SC P received the B.Eng degree in Electronic and Telecommunication and MSc degree in Electronic engineering from the University of Science and Technology, The University of Da Nang, Vietnam, in 2009 and 2016 respectively. She is currently lecturer of Vietnam - Korea Univesity of Information and Communication Technology. She can be contact at email: trangnth@ vku.udn.vn. 